\title{
Polygalacturonase production enhancement by Piriformospora indica from sugar beet pulp under submerged fermentation using surface methodology
}

\section{somayyeh Kiani}

University of Maragheh

parisa fathi rezaei ( $\triangle$ parisafathirezaei@gmail.com )

University of Maragheh https://orcid.org/0000-0003-0521-8669

sina jamalzadegan

North Carolina State University at Raleigh: NC State University

\section{Research Article}

Keywords: By-product, Optimization, Pectin, Polygalacturonase, Sugar beet pulp, Environmental pollution

Posted Date: March 1st, 2022

DOI: https://doi.org/10.21203/rs.3.rs-1239635/v1

License: () (i) This work is licensed under a Creative Commons Attribution 4.0 International License.

Read Full License 


\section{Abstract}

This study proposed a novel and cost-effective approach to enhance and optimize the polygalacturonase from $P$. indica. In current investigation, the impact of ammonium sulfate, sugar beet pulp (SBP) and glucose as variables on induction of polygalacturonase from $P$. indica was optimized using the central composite design (CCD) of response surface methodology (RSM) under submerged fermentation (SmF). Additionally, partial polygalacturonase purification and in situ analysis were performed. The optimal reaction conditions, which resulted in the highest enzyme activity were observed as the following conditions: ammonium sulfate (4 g/L), SBP (20 g/L), glucose (60 g/L). Under the optimized condition, the maximum enzyme activity reached to $19.4 \mathrm{U} / \mathrm{ml}(127 \mathrm{U} / \mathrm{mg})$ which increased by 5.84 times compared to non-optimized conditions. The partial purified polygalacturonase molecular weight was estimated 60 $\mathrm{KDa}$. In line with the bioinformatic analysis, exo-polygalacturonase sequence of $P$. indica showed similarity with Rhizoctonia solani's and Thanateporus cucumeris. These results indicated that SBP act as a cheap and suitable inducer of polygalacturonase production by $P$. indica in a submerged cultivation. The outcome of this study will be useful for industries to decrease environmental pollution with costeffective approaches.

\section{Introduction}

Nowadays, considering the global sensitivity about the environment, enzyme production from wastes, helped to overcome the problem of high-cost production in the industry and prevent environmental pollution (Tepe \&Dursun 2014). With the increasing application of pectinase, decreasing cost production has become one of the most important targets. Previous researches have mentioned that pectincontaining agro-wastes, including sugar beet pulp, citrus pulp pellets, apple pomace, henequen pulp, lemon pulp and other related materials as carbon source could induce pectinase production by many microorganisms (Bai et al. 2004). Sugar beet pulp (SBP) as the by-product of the beet sugar industry, is produced annually in large quantities. On the other hand, SBP could be an important renewable resource and its bio-conversion appears to be a great biotechnological advantage. The lignocellulosic portion of dried SBP is consist of $22-30 \%$ cellulose, $24-32 \%$ of hemicellulose (essentially arabinan), $24-32 \%$ of pectins substances and $3-4 \%$ of lignin (Hutnan et al. 2000). Due to high pectin content of SBP, it could be used for pectinolytic enzymes production without adding any pectinaceous materials as enzyme inducer (Nigam \&Pandey 2009).

Pectinases or pectin depolymerases known as a very important industrial enzymes have a broad range of applications in food, pharmaceutical, textile, processing and paper and pulp industries (John et al. 2020). The pectinolytic enzymes are produced by higher plants, bacteria, fungi, yeasts under submerged and solid-state fermentation conditions. They are classified regarding to their mechanism of action: pectin esterase, pectinase (polygalacturonase) and pectin lyase; and caused production of galacturonic acid (Patidar et al. 2018). Like many other depolymerizing enzymes, they are usually inducible by the polymer they could degrade. Among them, fungal pectinases have the greatest significance with extensive applications (Patil \&Dayanand 2006). The choice of source, substrate, reaction conditions and reactor 
design are the important factors in upstream pectinase production processing (John et al. 2020). Pectin as the acidic heteropolysaccharide is mainly composed of galacturonic acid which present the major components of middle lamella and primary cell wall of plants (Satapathy et al. 2020).

The induction of pectinase production by various organisms from agricultural by-products were described; by Penicillium fellutanum from wheat bran (Amin et al. 2021), by Bacillus pumilus from mixture of banana and orange peel (Viayaraghavan et al. 2019), by Aspergillus nigerDMF 27 and DMF 45 from deseeded sunXower head (Patil \&Dayanand 2006), by Aspergillus niger from citrus waste peel (Ahmed et al. 2016), by Aspergillus sojae from agricultural and agro-industrial residues (Heerd et al. 2014), by Aspergillus niger and Bacillus gibsoni from sugar beet pulp (Jacob 2009), by T. reesei Rut C-30 from sugar beet pulp (Olsson et al. 2003), and by Bacillus pumilus from sugar beet pulp and wheat bran (Tepe \&Dursun 2014).

In the current investigation, the production of exo-polygalacturonase from $P$. indica by sugar beet pulp (SBP) as an inducer was optimized by response surface methodology (RSM) and its molecular characteristics evaluated by partial purification and in situ analysis.

\section{Material And Methods \\ 2.1. SBP preparation}

SBP was prepared from Moghan Agro-Industry \& Livestock Co., dried at $60{ }^{\circ} \mathrm{C}$ for $24 \mathrm{~h}$, dried SBP grinded and stored in air tight container. The particles with mesh sieve size adjusted to $500 \mu \mathrm{m}$ were used for submerged fermentation.

\subsection{Microorganism, media and culture conditions}

The $P$. indica fungus was selected for production of polygalacturonase and obtained from the Department of Plant Pathology, School of Agriculture, Tarbiat Modares University (Iran). The fungi were cultured on modified Kaefer medium (Käfer 1977) and glucose was replaced with SBP. SBP ${ }^{+}$represents the SBP-containing medium.

For submerged cultivation of $P$. indica, $10 \mathrm{~mm}$ of agar discs were transferred to $250 \mathrm{~mL}$ flasks containing $50 \mathrm{~mL}$ of modified Kaefer medium supplemented with $10 \mathrm{~g} / \mathrm{L} \mathrm{SBP}$ and incubated in shaker $(200 \mathrm{rpm})$ at $29^{\circ} \mathrm{C}$ for 10 days. Medium without sugar beet pulp $\left(\mathrm{SBP}^{-}\right)$was used as control. The samples were assayed for pectinase activity and fungal growth measurement.

\subsection{Measurement of cell fresh and dry weight, growth yield and specific growth rate}

At the end of each incubation time, the culture broth was filtered through Whatman No. 1 paper and growth parameters including; growth yield $\left(\mathrm{Y}_{\mathrm{X} / \mathrm{S}}\right)$, specific growth rate $(\mu)$ and spore yield fresh and medium pH were determined (Kumar et al. 2011). 


\subsection{Total protein determination}

Protein content and pectinase activity were determined in the cell-free supernatant after centrifugation of

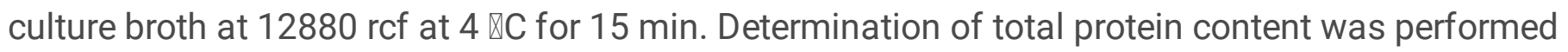
according to the Bradford's method and bovine serum albumin used as the standard (Bradford 1976).

\subsection{Pectinase activity}

Polygalacturonase activity was evaluated by measuring the released reducing end products, using 3, 5dinitrosalicylic acid (DNS) and expressed as galacturonic acid equivalent (Miller 1959). The enzymatic reaction mixture included $0.25 \mathrm{ml}$ of cell-free supernatant and $0.75 \mathrm{ml}$ of $1 \%$ pectin in $0.2 \mathrm{M}$ phosphate buffer $\mathrm{pH} 6.5$ as substrate. The mixture was incubated at $60^{\circ} \mathrm{C}$ for $5 \mathrm{~min}$. One unit $(\mathrm{U})$ was expressed in term of the enzyme quantity which would yield $1 \mu \mathrm{mol}$ galacturonic acid per minute during the standard assay condition.

\subsection{Identification of the significant variables using experimental design}

In order to maximize enzyme production and understand the role of interacting variables, optimization of the medium constituents was done by central composite design (CCD). Three variables including; glucose (A), ammonium sulfate (B) and SBP (C) were selected to find the optimized condition for the production of pectinase and twenty experimental runs with three center points generated including the response surface plot by using the statistical software package Design-Expert 7.0.0 (Stat Ease Inc., Minneapolis, USA). The range and the levels of the variables are given in Table 1. The recommended 20 experiments by using different composition of independent variables was shown in Table 2. Statistical analysis of the model was performed to evaluate the analysis of variance (ANOVA). The quality of the polynomial model equation was judged statistically by determination coefficient $R^{2}$, and its statistical significance was determined by F-test.

Table 1

Levels of independent variables used in CCD design.

\begin{tabular}{|llllll|}
\hline Variables & Units & Symbol code & \multicolumn{4}{l|}{ Levels } \\
\cline { 4 - 6 } & & & $-\mathbf{1}$ & $\mathbf{0}$ & $\mathbf{1}$ \\
\hline Glucose & $\mathrm{g} / \mathrm{L}$ & $\mathrm{A}$ & 60 & 80 & 100 \\
\hline Ammonium sulfate & $\mathrm{g} / \mathrm{L}$ & $\mathrm{B}$ & 6 & 4 & 8 \\
\hline Sugar beet pulp (SBP) & $\mathrm{g} / \mathrm{L}$ & $\mathrm{C}$ & 10 & 15 & 20 \\
\hline
\end{tabular}


Table 2

CCD design matrix for pectinase production factors and corresponding results.

\begin{tabular}{|c|c|c|c|c|c|c|c|c|c|}
\hline \multirow[t]{2}{*}{ Run } & \multicolumn{3}{|c|}{ Variables } & \multirow{2}{*}{$\begin{array}{l}\text { DW } \\
(g / L)\end{array}$} & \multirow{2}{*}{$\begin{array}{l}\text { FW } \\
(g / L)\end{array}$} & \multirow[t]{2}{*}{$\mathrm{pH}$} & \multirow{2}{*}{$\begin{array}{l}\text { Protein } \\
(\mathrm{mg} / \mathrm{ml})\end{array}$} & \multirow{2}{*}{$\begin{array}{l}\text { Observed } \\
\text { activity (U/ml) }\end{array}$} & \multirow{2}{*}{$\begin{array}{l}\text { Specific } \\
\text { activity (U/mg) }\end{array}$} \\
\hline & $A$ & B & C & & & & & & \\
\hline 1 & 60 & 4 & 20 & 62.56 & 417.85 & 4.09 & 0.25 & 19.41 & 77.64 \\
\hline 2 & 60 & 6 & 15 & 55.5 & 323.36 & 3.72 & 0.18 & 14.74 & 81.88 \\
\hline 3 & 80 & 6 & 15 & 62.06 & 332.6 & 3.55 & 0.157 & 12.33 & 78.53 \\
\hline 4 & 80 & 6 & 10 & 57.53 & 205.86 & 4.7 & 0.151 & 10.46 & 69.27 \\
\hline 5 & 100 & 4 & 20 & 60.85 & 380.85 & 3.78 & 0.196 & 14.16 & 72.24 \\
\hline 6 & 80 & 6 & 15 & 47.77 & 306.98 & 5.09 & 0.148 & 12.13 & 81.95 \\
\hline 7 & 100 & 6 & 15 & 64.39 & 245.88 & 5.76 & 0.135 & 10.76 & 79.70 \\
\hline 8 & 80 & 8 & 20 & 55.94 & 373.6 & 4.85 & 0.433 & 10.12 & 23.37 \\
\hline 9 & 80 & 8 & 15 & 55.335 & 369.56 & 5.06 & 0.217 & 10.67 & 49.17 \\
\hline 10 & 60 & 4 & 10 & 66.20 & 188.61 & 5.29 & 0.145 & 14.03 & 96.75 \\
\hline 11 & 80 & 4 & 15 & 57.11 & 381.42 & 4.28 & 0.148 & 14.03 & 94.79 \\
\hline 13 & 80 & 6 & 15 & 69.22 & 336.53 & 3.88 & 0.105 & 13.33 & 126.95 \\
\hline 14 & 60 & 8 & 20 & 53.35 & 253.26 & 5.60 & 0.252 & 12.35 & 49 \\
\hline 15 & 100 & 8 & 10 & 52.09 & 176.76 & 4.99 & 0.192 & 8.07 & 42.02 \\
\hline 16 & 100 & 4 & 10 & 56.19 & 251.20 & 4.69 & 0.133 & 9.78 & 73.53 \\
\hline 17 & 80 & 6 & 15 & 61.75 & 332.77 & 4.15 & 0.19 & 12.87 & 67.73 \\
\hline 18 & 80 & 6 & 15 & 73.40 & 323.33 & 4.84 & 0.26 & 12.54 & 48.23 \\
\hline 19 & 60 & 8 & 10 & 51.71 & 266.44 & 3.6 & 0.16 & 10.75 & 67.19 \\
\hline 20 & 80 & 6 & 15 & 58.99 & 393.97 & 5.17 & 0.11 & 12.37 & 111.45 \\
\hline
\end{tabular}

\subsection{Pectinase partial purification}

To purify the pectinase, the fungus was cultured in $250 \mathrm{~mL}$ shake flasks with $100 \mathrm{~mL}$ of optimized fermentation medium. The fermentation broth was separated by centrifugation at $10,000 \mathrm{~g}$ for $15 \mathrm{~min}$ at $4^{\circ} \mathrm{C}$ and the cell-free supernatant was saturated with ammonium sulphate to $90 \%$ saturation. The saturated solution was left overnight at $4^{\circ} \mathrm{C}$ with gentle agitation, centrifuged at $10000 \mathrm{~g}$ for $20 \mathrm{~min}$ at 4 ${ }^{\circ} \mathrm{C}$, the precipitate solubilized in minimal amount of $10 \mathrm{mM}$ sodium acetate buffer ( $\mathrm{pH}$ 5.75) and dialyzed against the same buffer for $24 \mathrm{~h}$ at $4^{\circ} \mathrm{C}$. The obtained-dialyzed proteins were used for enzyme characterization. The protein content and enzyme activity were determined as described in earlier part. 


\subsection{Gel electrophoresis}

The molecular mass and purity of polygalacturonase were determined by SDS-PAGE ( $12.5 \%$ running gel and 5\% stacking gel) Laemmli (1970) (Laemmli 1970). The protein samples were denatured by heating at $100^{\circ} \mathrm{C}$ with the sample buffer for $5 \mathrm{~min}$ before loading and the gel was stained by silver staining method of Merril et al (Merril et al. 1981).

\subsection{Phylogenetic tree simulation}

We applied Molecular Evolutionary Genetics Analysis (MEGA X) software as a powerful tool for constructing sequence alignments, gathering phylogenetic histories, and performing molecular evolutionary analysis. This software can be used for comparing DNA and protein sequences. Firstly, we aligned the DNA sequences of more than fifty different strain types of extracellular polygalacturonases and then a phylogenetic tree was constructed for those data by the maximum likelihood method. In this approach, an initial phylogenetic tree was constructed using a Neighbor-Joining, and its branch lengths are modified to maximize the likelihood of the data set for that tree topology under the desired model of evolution. Then the NNI (nearest neighbor Interchange) approach was used for creating the variants of the topology. NNI tries to search for topologies that are in good shape with the data better. The search is repeated until no greater likelihoods are found. Finally, the Neighbor-joining tree of different extracellular polygalacturonase strains was constructed after 500 iterations and the bootstrap confidence values were calculated and shown on node in Fig. 4. The protein sequences were gathered from Uniprot and GenBank (NCBI) (Kumar et al. 2018) (Chen et al. 2014)

(https://academic.oup.com/nar/article/22/22/4673/2400290?login=true). (Verma et al. 1998)

\section{Results}

\subsection{Growth of fungus}

Production of pectinase by $P$. indica was evaluated for 10 days (Fig. 1). The production of pectinase on both medium, reached its maximum rate on day 6 th of culture and then decreased. The production of enzyme on $\mathrm{SBP}^{-}$and $\mathrm{SBP}^{+}$medium was determined 2.2 and $3.32 \mathrm{U} / \mathrm{ml}$, respectively. Also, the highest amount of dry and fresh weight on both medium was detected on day 6 of culture (Fig. 1a and 1b). As shown in Table 3, the lowest and highest dry cell weight were detected on unmodified Kaefer medium and SBP- and glucose-containing medium, respectively. Furthermore, the highest amount of growth yield and specific growth rate were measured on medium containing ammonium sulfate, glucose and SBP, 0.62 and 1.61 respectively. 
Table 3

Effect of variables on growth of $P$. indica.

\begin{tabular}{|llll|}
\hline Culture medium & Maximum DCW $(\mathbf{g} / \mathbf{L})$ & $\mathrm{Y}_{\mathrm{x} / \mathrm{s}}(\mathbf{g} / \mathbf{g})$ & $\boldsymbol{\mu}\left(\mathbf{d}^{-1}\right)$ \\
\hline Medium & $3.7 \pm 0.1414$ & & \\
\hline Medium + SBP & $6.125 \pm 0.1768$ & 0.61 & 0.30 \\
\hline Medium + Ammonium sulphate & $3.95 \pm 0.21215$ & 0.28 & 1.27 \\
\hline Medium + Ammonium sulphate + SBP & $7.675 \pm 0.1768$ & 0.54 & 0.61 \\
\hline Medium + Glucose & $15.625 \pm 1.096$ & 0.26 & 0.45 \\
\hline Medium + Glucose + SBP & $26.45 \pm 1.202$ & 0.44 & 0.54 \\
\hline Medium + Ammonium sulphate + Glucose + SBP & 73.40 & 0.62 & 1.61 \\
\hline 3.2 Optimization Of the pectinase production by RSM & \\
\hline
\end{tabular}

Three factors that have the maximum effect on the polygalacturonase production were determined by one-factor-at-a-time method and the interaction between various selected factors on polygalacturonase production (glucose, ammonium sulfate and SBP concentration) were investigated by RSM.

Then the results were analyzed by standard analysis of variance (ANOVA) and the CCD design was fitted with the second-order polynomial equation:

$\mathrm{Y}(\mathrm{U} / \mathrm{ml})=+14.44655-0.25632 \times \mathrm{A}-0.050858 \times \mathrm{B}+1.78328 \times \mathrm{C}+0.010096 \times \mathrm{A} \times \mathrm{B}-2.36660 \mathrm{E}-003 \times \mathrm{A}$ $\times C-0.094896 \times B \times C+8.28012 E-004 \times A^{2}-0.031692 \times B^{2}-0.024311 \times C^{2}$

Eq. (1) polygalacturonase activity $(\mathrm{Y})$ as a function of Glucose $(\mathrm{A})$, Ammonium sulfate $(\mathrm{B})$ and Sugar beet pulp (C).

The software suggested 20 experiments and the predicted and experimental values for enzyme production are presented in Table 2 . The sufficiency of the model was checked using correlation coefficient $\left(R^{2}\right)$ and the closer the value of $R^{2}$ to 1 , the better the correlation between the observed and the predicted values. The correlation coefficient $\left(R^{2}\right)$ which shows the relationship between the experimental and predicted responses was 0.9866 and thus the model could explain more than $98.66 \%$ of the variability in the responses (Table 4). 
Table 4

ANOVA for response surface quadratic model of polygalacturonase production.

\begin{tabular}{|c|c|c|c|c|c|c|}
\hline Source & Sum of squares & df & Mean squares & F value & $P$ - value & \\
\hline Model & 106.59 & 9 & 11.84 & 81.76 & $<0.0001$ & significant \\
\hline A & 29.23 & 1 & 29.23 & 201.82 & $<0.0001$ & \\
\hline B & 38.49 & 1 & 38.49 & 265.70 & $<0.0001$ & \\
\hline C & 19.13 & 1 & 19.13 & 132.08 & $<0.0001$ & \\
\hline$A B$ & 0.92 & 1 & 0.92 & 6.35 & 0.0304 & \\
\hline$A C$ & 0.32 & 1 & 0.32 & 2.18 & 0.1705 & \\
\hline$B C$ & 6.14 & 1 & 6.14 & 42.37 & $<0.0001$ & \\
\hline$A^{2}$ & 0.31 & 1 & 0.31 & 2.15 & 0.1733 & \\
\hline$B^{2}$ & 0.047 & 1 & 0.047 & 0.32 & 0.5829 & \\
\hline$c^{2}$ & 1.07 & 1 & 1.07 & 7.40 & 0.0215 & \\
\hline Residual & 1.45 & 10 & 0.14 & - & - & \\
\hline Lake of Fit & 0.50 & 5 & 0.10 & 0.53 & 0.7483 & Not significant \\
\hline Pure error & 0.95 & 5 & 0.19 & & & \\
\hline Cor total & 108.04 & 19 & - & - & - & \\
\hline
\end{tabular}

Moreover, $R^{2}$ values were in reasonable agreement with adjusted $R^{2}$ values of 0.9745 (polygalacturonase production). Values greater than 0.1000 indicate the model terms are not significant. The "Pred R-

Squared" of 0.9404 is in reasonable agreement with the "Adj R-Squared" of 0.9745. Table 4 represents the obtained results of the quadratic response surface model fitting in the form of ANOVA.

The model F-value is 81.76 which indicates the model significance. The (B) had the highest F-value of 265 implying that it had the most significant influence on the enzyme activity in comparison to glucose $(A)$ and SBP (C). Moreover, the lack of fit F-value was 0.53 which is nonsignificant relative to the pure error. The model is geared toward perfect fitness.

\subsection{Interaction between operating factors}

According to the ANOVA Table 4, the significancy of the independent variables and interaction between them was determined by F-values and $p$-values. As seen in Table 4, A, B, C, AB and BC with a very small pvalue $(p<0.05)$ were significant while, $A C$ was insignificant on enzyme production. 
Due to the positive linear coefficient of SBP, by increasing the SBP concentration within the range assayed the enzyme production increased. Also the negative quadratic coefficients of ammonium sulfate and SBP explain the maximum enzyme production at these levels. Subsequently, the enzyme production decreased out of this point. In accordance with the coefficients, SBP is determined as the factor which has the most positive impact on enzyme production.

Furthermore, the interaction among variables was confirmed by the 3-D response surface plots which is used to identify the optimum levels. The interaction between variables were also evaluated in pectinase production.

The 3-D plots represent the interaction between the two factors, while the other factor was fixed at its optimum level for maximum enzyme production (Fig. 2). Fig. 2a exhibits the interaction between ammonium sulfate and glucose, reveals an increase in pectinase production by increasing in ammonium sulfate and glucose concentrations. The response between glucose and SBP indicated that increasing the SBP content and decreasing glucose concentration led to higher enzyme production (Fig. 2.b). The plot for the interaction between SBP and ammonium sulfate (Fig. 2c) showing an increase in enzyme production at low level of ammonium sulfate and high level of SBP.

The maximum enzyme production was occurred at high levels of SBP and low levels of glucose and ammonium sulfate.

Effect of 3 factors on the response were significant $(P>0.05)$ which showed higher and effective contribution to the enzyme production in $\mathrm{SmF}$ (Table 4).

Further, the optimum condition for pectinase production obtained at $60 \mathrm{~g} / \mathrm{L}$ of glucose, $4 \mathrm{~g} / \mathrm{L}$ of ammonium sulfate and $20 \mathrm{~g} / \mathrm{L}$ of SBP. At the optimum condition, the enzyme activity increase to 19.41 $\mathrm{U} / \mathrm{ml}$ which is 5.58 -fold more than unoptimized condition.

\subsection{Partial purification of pectinase}

For purification, the supernatant was precipitated by ammonium sulfate. The partial purification results were shown in Table 5. Then the specific activity and fold purification was calculated 63.77 and 0.82 $(\mathrm{U} / \mathrm{mg})$ respectively. The molecular mass of pectinase was found around $60 \mathrm{kDa}$ by SDS-PAGE (Fig. 3).

Table 5

Partial purification process of pectinase.

\begin{tabular}{|llllll|}
\hline Purification step & $\begin{array}{l}\text { activity } \\
(\mathrm{U} / \mathrm{ml})\end{array}$ & $\begin{array}{l}\text { protein } \\
(\mathrm{mg} / \mathrm{ml})\end{array}$ & $\begin{array}{l}\text { Specific activity } \\
(\mathbf{U} / \mathbf{m g})\end{array}$ & $\begin{array}{l}\text { Recovery } \\
(\%)\end{array}$ & $\begin{array}{l}\text { Purification } \\
\text { fold }\end{array}$ \\
\hline Crude extraction & 19.40 & 0.25 & 77.6 & 100 & 1 \\
\hline $\begin{array}{l}\text { Ammonium sulfate } \\
\text { precipitation }\end{array}$ & 11.48 & 0.18 & 63.77 & 59.05 & 0.82 \\
\hline
\end{tabular}

\subsection{Simulation results}


As shown in Fig. 4, the phylogenetic tree gathered from the concatenated rDNA and TEF alignment by applying heuristic $\mathrm{ML}$ analysis with the bootstrap values are shown on nodes. We compared the phylogenetic relationships of $P$. indica with Rhizoctonia solani's extracellular polygalacturonases in NCBI data bank. In Fig. 5, Rhizoctonia solani's and Thanateporus cucumeris revealed exo-polygalacturonases similar sequences. Also in Fig. 6 we showed the alignment of the predicted amino acids sequences of $P$. indica polygalacturonase with 8 similar sequences.

\section{Discussion}

Nowadays, over the global there is a great interest to obtain pectinase from cheap and suitable substrates like agricultural residues.

Here the efficiency of $P$. indica in biodegradation of SBP has been evaluated. Subsequently, the polygalacturonase activity on $\mathrm{SBP}^{+}$and $\mathrm{SBP}^{-}$media has been reported for 10 days (Fig. 1). The polygalacturonase production and fungal growth reached the maximum level simultaneously on both medium. It's stablished that the components of the medium have great effect on the induction of pectolytic enzymes. Several substances play an inducer role on these enzymes synthesis (Nair \&Panda 1997). The utilization of agro-industrial residues, like apple pomace and sugar beet pulp, further could solve environmental problems of the by-products (Heerd et al. 2014). The choice of perfect agricultural residue to induce enzyme production depends on several factors, such as cost and availability of the substrates. It is known that duration of fermentation depends on the medium composition, organism, concentration of nutrients and the physiological conditions (Patil \&Dayanand 2006).

SBP has been used as raw material to induce pectinase production by Aspergillus niger. Additionally it has been used as carbon source as well as pectinase inducer to produce extracellular alkaline pectinase, by Bacillus gibsoni, under SSF (Jacob 2009). Cultivation of T. reesei Rut C-30 on sugar beet pulp ( $50 \mathrm{~g} / \mathrm{L}$ ), the protein content, pectinase activity and specific activity reached their maximum value after $60 \mathrm{~h}$ of fermentation $(0.43 \mathrm{~g} / \mathrm{l}, 0.82 \mathrm{U} / \mathrm{ml}$ and $1.9 \mathrm{U} / \mathrm{mg}$ respectively) (Olsson et al. 2003). The highest enzyme activity by $A$. sojae on $30 \%$ sugar beet pulp as an inducer and wheat bran as medium wetted agent attained after 8 days (Heerd et al. 2014).

However our results show the highest activity of exo-pectinase in medium containing sugar beet pulp determined $3.4 \mathrm{U} / \mathrm{mL}$ on $96 \mathrm{~h}$ of fermentation and following optimization it reaches to $19.41 \mathrm{U} / \mathrm{ml}$.

The greatest endo- and exo-pectinase activity by $A$. niger from sunflower head in SSF $(5.1 \mathrm{U} / \mathrm{g}$ and $17.1 \mathrm{U} / \mathrm{g})$ and $\mathrm{SmF}(4.5 \mathrm{U} / \mathrm{ml}$ and $16.0 \mathrm{U} / \mathrm{ml})$ were measured on $96 \mathrm{~h}$. According to the different studies about the fermentation time, it exhibited wide range $40-120 \mathrm{~h}$ and $90-120 \mathrm{~h}$ in submerged and solid state fermentations, respectively (Patil \&Dayanand 2006).

The Colletotrichum isolated from Argentinian soybean, yielded high amount of the PG $(1.08 \mathrm{U} / \mathrm{ml})$ after 7-10 days of incubation and coincide with maximum growth. In medium involving glucose as a sole carbon source decreased polygalacturonase production was monitored (Ramos et al. 2010). 
Environmental and nutritional factors are known as two essential factors which affect enzyme production by microorganisms. The pectin and polygalacturonic acid applied as only source of carbon in the medium which induced synthesis of pectinolytic enzymes by $A$. niger and there was no pectolytic activity in medium containing glucose as an only carbon source. Production of pectin degrading enzymes in the presence of pectin and high glucose concentrations were inhibited although glucose in low concentrations promoted their production. The observed low pectinolytic activity in media with high glucose concentrations is possibly due to provide growth need of organism by the glucose consumption and caused to decrease the pectin lysis. Furthermore, at low glucose concentrations, high pectolytic activity were observed (Fawole \&Odunfa 2003). In agreement with Fawole et al, Our results showed the highest pectinolytic activity was attained at the lowest glucose concentration $(60 \mathrm{~g} / \mathrm{L})$.

Pectinolytic activity by $A$. niger on medium containing pectin, poly galacturonic acid and glucose at $30^{\circ} \mathrm{C}$ for 5 days was 17.2, 13.8 and $0 \mathrm{U} / \mathrm{ml}$, respectively (Fawole \&Odunfa 2003).

As it is shown by Aguilar and Huitron (1987) high exogenous glucose and galacturonic acid could be influenced endo-PG enzyme production by catabolite repression, whereas glucose had no effect on the exo-PG. The Glucose concentration above $10 \%(\mathrm{w} / \mathrm{w})$ in the SSF, decreased noticeably the activity of endo and exo-PG (Aguilar \&Huitrón 1990).

In Solis-Pereyra et al study, exo-PG/gdm and endo-PG/gdm activity by $A$. niger on medium containing $16 \%(\mathrm{w} / \mathrm{w})$ citric pectin, were $281 \mathrm{U}$ and $152 \mathrm{U}$. Moreover, inhibited enzyme production and growth were detected on 20-30\% (w/w) pectin concentration (Fontana et al. 2005).

Ammonium sulphate was introduced as the favourable nitrogen source for pectinase production by $A$. niger (Fawole \&Odunfa 2003). Our results are in concurrence with the observations of Sapunova who also demonstrated that ammonium salts could act as stimulator of the pectinase. It has been described that nitrogen limitation decreases the production of polygalacturonase (Thakur et al. 2010).

Bai and et al, examined the impact of different nitrogen sources on pectinase induction and great enzyme activity measured with ammonium sulfate, yeast extract, soya peptone, soya pulp and MGW(Bai et al. 2004).

Patil and et al examined the impact of ammonium phosphate and sulphate on pectinase production by $A$. niger from sunflower head in both SSF and SmF. As their study revealed, ammonium phosphate and sulphate could increases the production of pectinase in both fermentation conditions. However, this increase was very less with ammonium phosphate in comparison to ammonium sulphate. The maximum production of endo-pectinase and exo-pectinase by DMF 27 were recorded in $\mathrm{SmF}$ condition $18.9 \mathrm{U} / \mathrm{ml}$ and 30.3 U/ml respectively (Patil \&Dayanand 2006).

As stated in many studies the average molecular mass of polygalacturonase are in the range of 35-80 $\mathrm{KDa}$ (John et al. 2020). Different microbial species produced different molecular mass of pectinase enzyme. Different factors such as the substrate, nature of microorganism, host cell wall and analytical 
methods results in different mass of pectinase (Oyede, 1998). The molecular weight of $P$. indica polygalacturonase in our study was comparable with previous reports.

\section{Conclusion}

The present study showed that optimized conditions by RSM, yielded high polygalacturonase activity by $P$. indica and SBP was established as a significant enzyme inducer substrate. In situ analysis confirmed the similarity of exopolygalacturonse of $P$. indica with $R$. solanis enzyme. Application of agricultural and agro-industrial wastes could be great source for enzyme production, because economically is valuable and decrease environmental pollution. The outcome of the proposed research will open up future pathways for using raw wastes materials to produce valuable products with cost-effective and ecofriendly approaches.

\section{Declarations}

\section{Acknowledgment}

We wish to acknowledge the Management of Research and Technology and the Central laboratory of University of Maragheh for their help in running the experiments.

\section{Availability of data and materials}

All data and materials are available.

\section{Authors Contributions}

Conceptualization, formal analysis, writing - review and editing, project administration, supervision: Parisa Fathi Rezaei. Material preparation, data collection and analysis, writing-original draft preparation: Somayyeh Kiani. Bioinformatic analysis: Sina Jamalzadegan.

All authors read and approved the final manuscript.

\section{Funding}

Partial financial support was received from University of Maragheh.

\section{Ethical Approval}


We the undersigned declare that this manuscript is original, has not been published before and is not currently being considered for publication elsewhere. We confirm that the manuscript has been read and approved by all named authors and that there are no other persons who satisfied the criteria for authorship but are not listed. We further confirm that the order of authors listed in the manuscript has been approved by all of us. We understand that the Corresponding Author is the sole contact for the Editorial process. She is responsible for communicating with the other authors about progress, submissions of revisions and final approval of proofs Signed by all authors as follows:
Name
Signature
Date

Somayyeh Kiani

kiani

$12 / 10 / 2021$

Parisa Fathi Rezaei

Fathi Rezaei

$12 / 10 / 2021$

Sina Jamalzadegan

Sina Jamalz

$12 / 10 / 2021$

\section{Consent to Participate}

The authors are consent to participate the article.

Consent to Publish

The authors are consent to publish the article.

\section{Competing interests}

The authors declare that they have no conflict of interest.

\section{References}

1. Aguilar G, Huitrón C (1990) Constitutive exo-pectinase produced by Aspergillus sp. CH-Y-1043 on different carbon source. Biotechnol Lett 12:655-660

2. Ahmed I, Zia MA, Hussain MA, Akram Z, Naveed MT, Nowrouzi A (2016) Bioprocessing of citrus waste peel for induced pectinase production by Aspergillus niger; its purification and characterization. Journal of Radiation Research and Applied Sciences 9:148-154

3. Amin F, Arooj T, Nazli Z, Bilal M (2021) : Exo-polygalacturonase production from agro-waste by Penicillium fellutanum and insight into thermodynamic, kinetic, and fruit juice clarification.Biomass 


\section{Conversion and Biorefinery, $1-11$}

4. Bai Z, Zhang H, Qi H, Peng X, Li B (2004) Pectinase production by Aspergillus niger using wastewater in solid state fermentation for eliciting plant disease resistance. Bioresour Technol 95:49-52

5. Bradford MM (1976) A rapid and sensitive method for the quantitation of microgram quantities of protein utilizing the principle of protein-dye binding. Anal Biochem 72:248-254

6. Chen Y, Sun D, Zhou Y, Liu L, Han W, Zheng B, Wang Z, Zhang Z (2014) Cloning, expression and characterization of a novel thermophilic polygalacturonase from Caldicellulosiruptor bescii DSM 6725. Int J Mol Sci 15:5717-5729

7. Fawole O, Odunfa S (2003) Some factors affecting production of pectic enzymes by Aspergillus niger. Int Biodeterior Biodegrad 52:223-227

8. Fontana RC, Salvador S, Silveira MMd (2005) Influence of pectin and glucose on growth and polygalacturonase production by Aspergillus niger in solid-state cultivation. J Ind Microbiol Biotechnol 32:371-377

9. Heerd D, Diercks-Horn S, Fernández-Lahore M (2014) Efficient polygalacturonase production from agricultural and agro-industrial residues by solid-state culture of Aspergillus sojae under optimized conditions. SpringerPlus 3:1-14

10. Hutnan M, Drtil M, Mrafkova L (2000) Anaerobic biodegradation of sugar beet pulp. Biodegradation $11: 203-211$

11. Jacob N (2009) Pectinolytic enzymes, Biotechnology for Agro-Industrial Residues Utilisation. Springer, pp 383-396

12. John J, Kaimal KS, Smith ML, Rahman PK, Chellam PV (2020) Advances in upstream and downstream strategies of pectinase bioprocessing: A review. Int J Biol Macromol 162:1086-1099

13. Käfer E (1977) Meiotic and mitotic recombination in Aspergillus and its chromosomal aberrations. Adv Genet 19:33-131

14. Kumar S, Stecher G, Li M, Knyaz C, Tamura K (2018) MEGA X: molecular evolutionary genetics analysis across computing platforms. Mol Biol Evol 35:1547

15. Kumar V, Sahai V, Bisaria V (2011) High-density spore production of Piriformospora indica, a plant growth-promoting endophyte, by optimization of nutritional and cultural parameters. Bioresour Technol 102:3169-3175

16. Laemmli UK (1970) : Cleavage of structural proteins during the assembly of the head of bacteriophage T4. nature 227, 680-685

17. Merril CR, Goldman D, Sedman SA, Ebert MH (1981) Ultrasensitive stain for proteins in polyacrylamide gels shows regional variation in cerebrospinal fluid proteins. Science 211:1437-1438

18. Miller GL (1959) Use of dinitrosalicylic acid reagent for determination of reducing sugar. Anal Chem $31: 426-428$

19. Nair S, Panda T (1997) Statistical optimization of medium components for improved synthesis of pectinase by Aspergillus niger. Bioprocess Biosyst Eng 16:169-173 
20. Nigam PS-N, Pandey A (2009) Biotechnology for agro-industrial residues utilisation: utilisation of agro-residues. Springer Science \& Business Media

21. Olsson L, Christensen TM, Hansen KP, Palmqvist EA (2003) Influence of the carbon source on production of cellulases, hemicellulases and pectinases by Trichoderma reesei Rut C-30. Enzym Microb Technol 33:612-619

22. Patidar MK, Nighojkar S, Kumar A, Nighojkar A (2018) Pectinolytic enzymes-solid state fermentation, assay methods and applications in fruit juice industries: a review. 3 Biotech 8:1-24

23. Patil SR, Dayanand A (2006) Production of pectinase from deseeded sunflower head by Aspergillus niger in submerged and solid-state conditions. Bioresour Technol 97:2054-2058

24. Ramos AM, Gally M, García MC, Levin L (2010) Pectinolytic enzyme production by Colletotrichum truncatum, causal agent of soybean anthracnose. Revista Iberoamericana de Micología 27:186-190

25. Satapathy S, Rout JR, Kerry RG, Thatoi H, Sahoo SL (2020) Biochemical prospects of various microbial pectinase and pectin: an approachable concept in pharmaceutical bioprocessing. Frontiers in Nutrition 7:117

26. Tepe O, Dursun AY (2014) Exo-pectinase production by Bacillus pumilus using different agricultural wastes and optimizing of medium components using response surface methodology. Environ Sci Pollut Res 21:9911-9920

27. Thakur A, Pahwa R, Singh S, Gupta R (2010) : Production, purification, and characterization of polygalacturonase from Mucor circinelloides ITCC 6025. Enzyme research 2010, 1-7

28. Verma S, Varma A, Rexer K-H, Hassel A, Kost G, Sarbhoy A, Bisen P, Bütehorn B, Franken P (1998) Piriformospora indica, gen. et sp. nov., a new root-colonizing fungus. Mycologia 90:896-903

29. Viayaraghavan P, Jeba Kumar S, Valan Arasu M, Al-Dhabi NA (2019) Simultaneous production of commercial enzymes using agro industrial residues by statistical approach. J Sci Food Agric 99:2685-2696

\section{Figures}



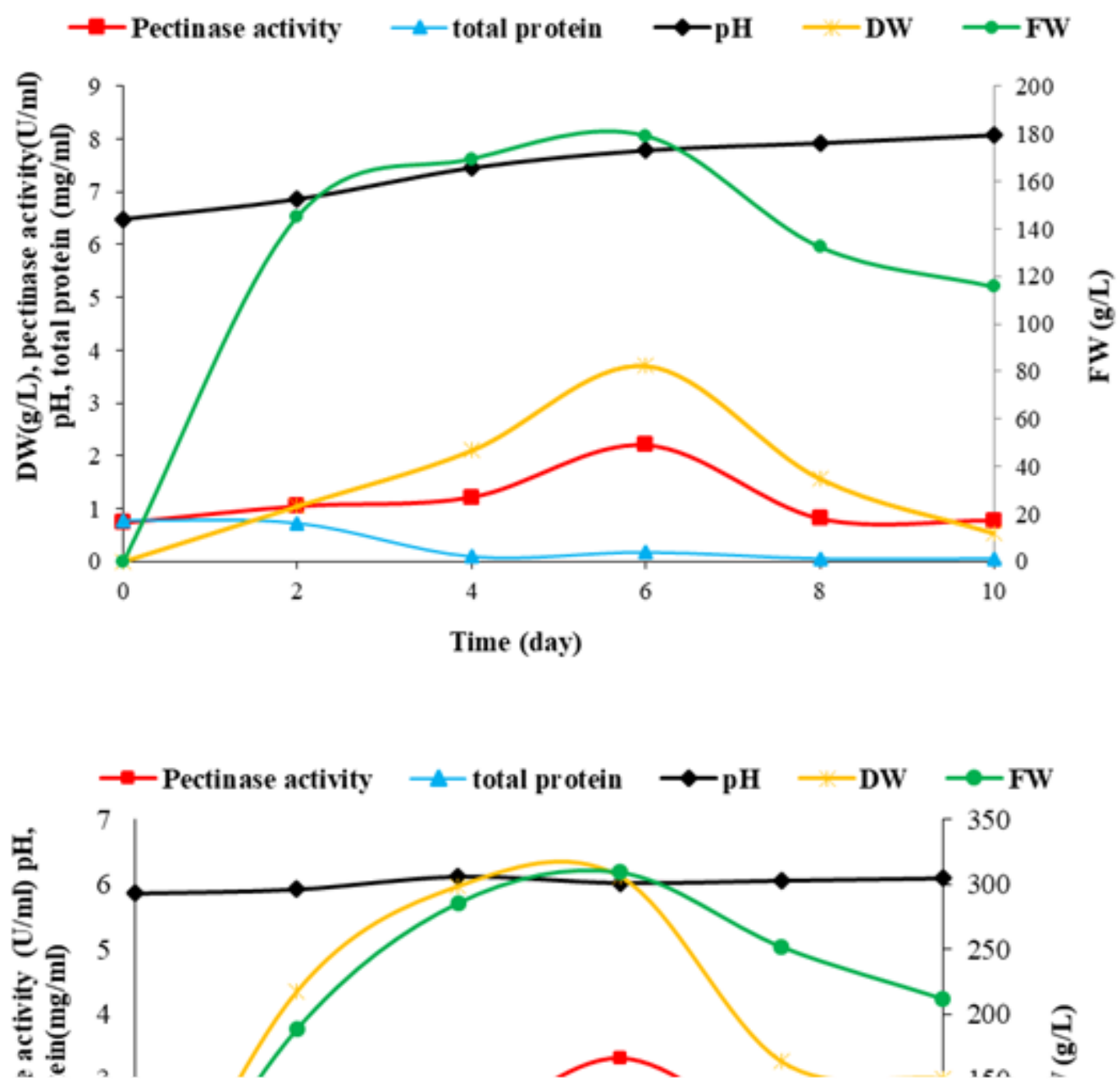

b)

\section{Figure 1}

The effect of SBP on growth parameters and pectinase activity of $P$. indica. Time course profile of $P$. indica on Kaefer medium (a) and supplemented with SBP (b) in SmF. Data are shown as mean \pm SD of three independent experiments in triplicate layout. SBP ${ }^{+}$: medium containing SBP, SBP: medium without SBP, FW: Fresh weight; DW: dry weight. 


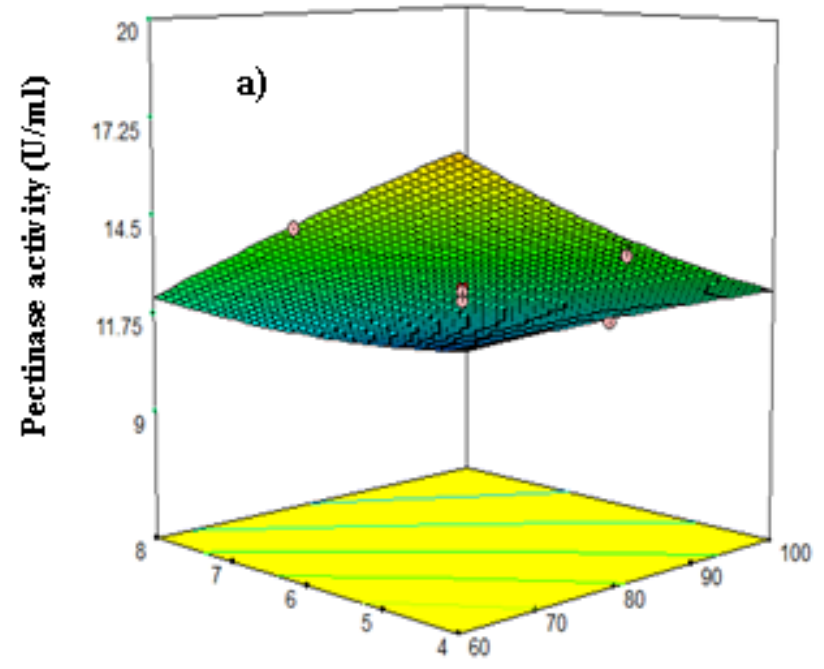

B: Ammonium sulphate $(\mathrm{g} / \mathrm{L})$

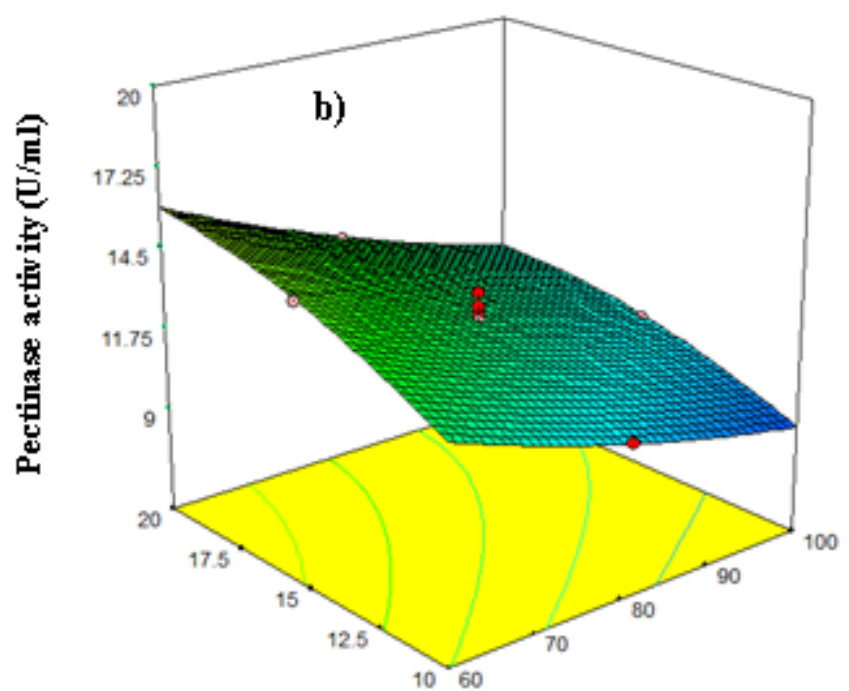

C: Sugar beet pulp (g/L)

A: Glucose $(g / L)$

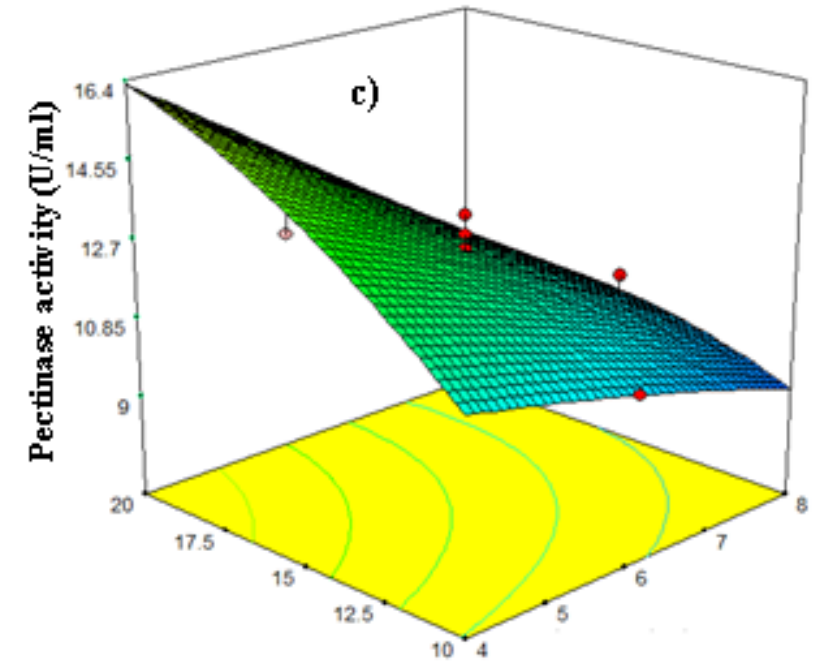

C: Sugar beet pulp (g/L) B: Ammonium sulphate (g/L)

\section{Figure 2}

Response surface plot of polygalacturonase yield under optimal conditions and interaction between variables. a) interaction between ammonium sulfate and glucose; b) interaction between sugar beet pulp and glucose; and c) interaction between sugar beet pulp and ammonium sulfate. 


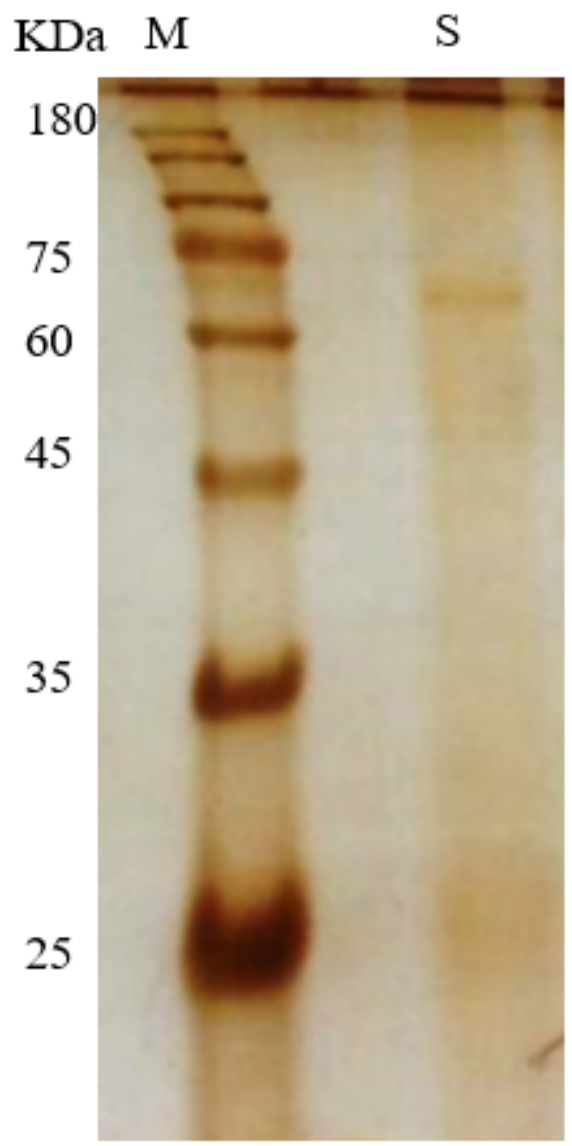

\section{Figure 3}

SDS-PAGE analysis of polygalacturonase. M: protein molecular weight marker; S: the sample after partial purification.

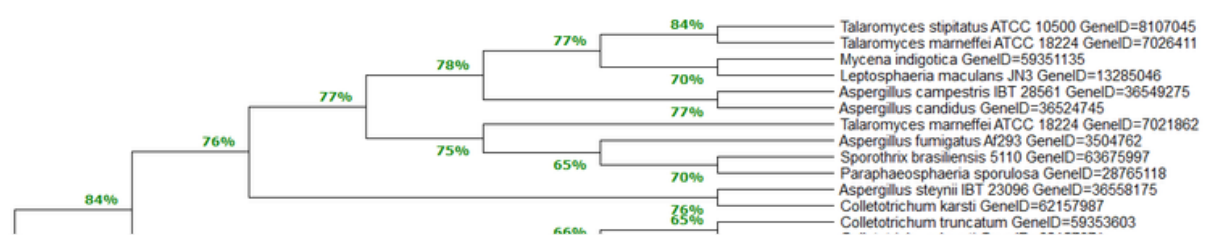

Figure 4 
Phylogenetic tree of the $P$. indica and closely related proteins created using the neighbor-joining method. Bootstrap confidence values (500 repetitions) are shown on nodes. The numbers at each node marked the percentage of supporting bootstrap samples.

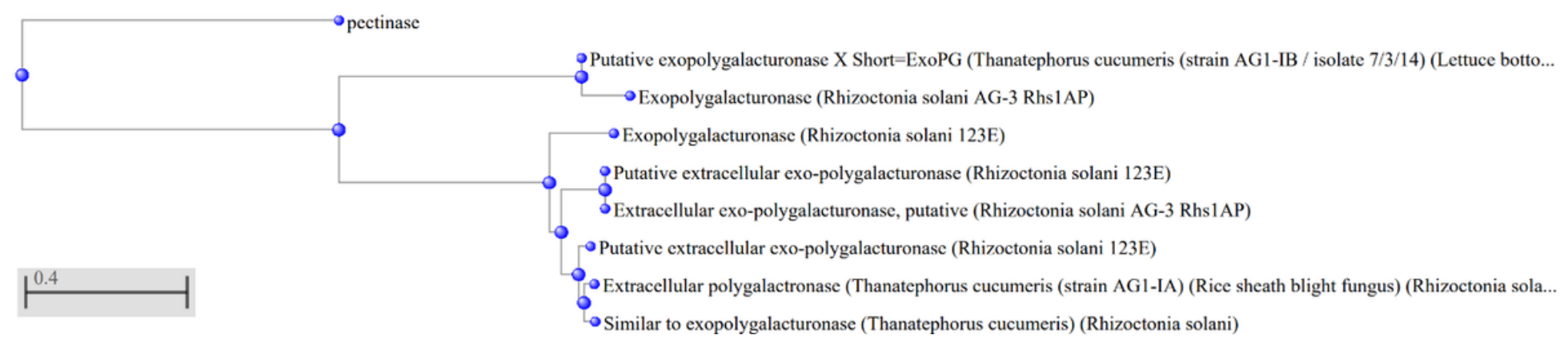

\section{Figure 5}

The phylogenetic tree represents similar DNA sequences to the polygalacturonase gene of $P$. indica. The protein sequences were retrieved from Uniprot and GenBank (NCBI). 
Query_10001 1 .................-NSLQKIKEEI-LKTLKVP[13]ADGSGKKDATGAIQKAIDQAHKagGGRVAVPEG-... 63 Query_10002 1 -.-MLS LFFALLGATSAVALVDSVERYTNPQTCIVP SYGNLNKSDTPAIHAAFKKCGK--GGRIIFKENTTYA 68 Query_10003 11 --MLS[1]FFTAALGATTVVSVDLAERYSNPQTCIIP SYGDLNKSDTPAIHAAFKKCGK--GGRIIFKENTTYA 69 Query_10004 1 -.-NFS[4]IFTAILGVTTAVASLGLTERQTSTTTCIVP SRGDLTKSDTPAIHAAFKKCGH--NGRIIFQKNTIYA 72 Query_10005 1 -.-NFS[4]IFTAILGVTTAVASLGLTERQTSTTTCIVP SRGDLTKSDTPAIHAAFKKCGH--NGRIIFQKNTIYA 72 Query_10006 1 -.-MLS[1]FF-AALSATTAMATVGSAERYTNPQTCIVP SYGNLNKSDTPAIHAAFKKCGK--GGRIIFKQNTTYA 68 Query_10007 Query_10008 1 mk1QLA[1]-IALALSPCVIADSKQNAKWTD-.....-IK SRGK-DKDDAPYLAKALKS-...--NARVRVPKGTILN 61 Query_10009 1 ..-MLS[1]LLTLALGVTAVLASKGGSK-..-PQTCIVP SHNWVNSDASAVHAAFKKCGK--GGRIVFSENTNYT 65

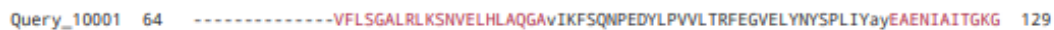
Query_10002 69 LNELTILTPCKSCTVELEGTLRLSDNITYWLKNAT-NPANLTSATYPNL -.................--DWK--KSSLIVSKTGKG 130 Query_10003 70 LNELTVLTPCKSCTVELEGTLRLSDNIAYMLKNAT-NPANLTSATYPNLVYYPFQDTFAYLILKDWK--KSSLVSKTGKG 146 Query_10004 73 LNELTIFTPCKGCTVELEGTLRLSDNWKYMLRNAT-DTKNLSSATYPNLVYYPFQDTVAYLILKDWE--NASLVSNTGKG 149 Query_10005 73 LNELTIFTPCKGCTVELEGTLRLSDNMKYMLRNAT-DTKNLSSATYPNLVYYPFQDTVAYLILKOWE--NASLVSNTGKG 149 Query_10006 69 LNELTMUTPCKSCTVELEGTLRLSDNITYZLKNAT-NPANLTSATYPNLVYYPFQDTFSYLILKDNK--KSSLVSKTGKG 145 Query_10007 11 ...--MNTTGLFGTHLRLEGTLRVKPDFAYWMGNAF-................-AVPYQRNSAIWLF-.....-GGENIVLDGGG 55 Query_10008 62 IATANTTGLFGTHLRLEGTLRVKPDFAYWAGNAF-...............-AVPYQKNSAIWLF-.....-GGENIVIDGGG 120 Query_10009 66 LGELTTMAPCIGCTVQLEGTIQLSDNLTYWLKNETINTPNITAETFPHLVYYPFQDTVAYLILKDWS--HSTLISKTGKG 143

Query_10001 130 TLDGQGDdeHWNPWKRG[25]ERQFGKGHYLRPNFIQPYRCKDILIQGVPVLNSPMNQVHPVLCENVTVDGIKVIGHG-- 228 Query_10002 131 LIDGAGQ--LWWMAFAG QEALDPGSLRRPVLFTVDGADKVSIDNVAMKNPANWFNNVIDSKYLNYTNIRLSALSTN 204 Query_10003 147 LIDGAGQ--LWWMAFAG QEALDPGSLRRPVLFTVDNADKVSIDNIAMKNPANWFNNTDSKYLNYTNIRLSAASAN 220 Query_10004 150 LIDGAGQ--LWWNAFAG QEILSPGSLRRPVLFTVDNANRVLIDNITLKNPANNFNNTDSSKYLNYTNIRLSALSTN 223 Query_10005 150 LIDGAGQ--LWMNAFAG QEILSPGSLRRPVLFTVDNANRVLIDNITLKNPANNFNNVTDSKYLNYTNIRLSALSTN 223 Query_10006 146 LIDGAGQ--LWWNAFAG QEALDPGSLRRPVLFTVDGADKVSIDNNAMKNPANNFNNVIDSKYITYTNIRLSALSAN 219 Query_10007 56 TIDGSGQ--SWWDARPG N-...-ASLIPPLTLVIHQAHNARVSNITFYKTPKNANLVQESSOWVYEYITVNSVSNS 124 Query_10008 121 TIDGSGQ--SWWDARPS N-...-ASLIPPLTLWWMSHWVRISNITFYKTPKWANLIQESSDIWEVYITVNSVSNS 189 Query_10009 144 LIDGLGQ--AMWDAAVG QQILIPGTLRRPVLFTLDGANWVTVDNVAMRNPANNFNNVIDSKNWLYKNIRLSALSSN 217

Query_10001 $229 \quad$...-PNTDGVNPESCKNWVIKGCHFDSGDDCIAVKSGRN[11]NIVIEHNEMKDGHGgVTIIGSEISGG-...-VKNVIAE 306 Query_10002 205 KNPPKNADGWDTYRTSHFVLRGAHVVSGDDCFSFKGNST NVTVEDVYCONSHG-VSVGSLAQYPGVLDRVEHVKVR 279 Query_10003 221 KNPPKNADGNDTYRTSHFVLRGAHVVSGDDCFSFKGNST IVTVEDVYCQNSHG-VSVGSLAQYPGVQDRVEHVKVR 295 Query_10004 224 KNPPKNMDGWDTYRTSHFTLRGAHVVSGDDCFAFKGNST YITVEDVYCONSHG-VSWGGLAQYRGVQDIVEHVKVK 298 Query_10005 224 KNPPKNADGWDTYRTSHFTLRGAHVVSGDDCFAFKGNST YITVEDVYCONSHG-VSVGGLAQYRGVQDIVEHVKVK 298 Query_10006 220 KNPPKNADGMDTYRTSHFVLRGAHVVSGDDCFSFKGNST NVTVEDVYCQNSHG-VSVGSLAQYPGVLDRVEHVKVR 294 Query_10007 125 TADMRETDGMDTYRSDGITIROSIIHNGDDCVSFKPNST NIVVRNLQCTESHG-ISVGSLGEIPGVKDIVRNIYVD 199 Query_10008 190 TADMRETDGNDTYRSDGITIROSIIHNGDDCVSFKPNST NWVVRNLQCTESHG-ISVGSLGEIPGVKDIVRNIYVD 264 Query_10009 218 KNPPANADGWDTYRTSHFELRDSHVVSGDDCFAFKGNST WVTIENVYCQNSHG-ISWGSLAQYPGVLDVVEHVKVK 292

Query_10001 307 GNLMDS--PNLDRALRIKTNSVRG---GVLENIYFHIOVTVKSLKREVIAIDMEYEEGDAGDF----KPVVR---NIDVEQL 375 Query_10002 280 NITFVGNGDSSSNGARIKIWAGPV-GSATVNDIHYEDLTVDNVT-NPLVVDSCYFSQAYCAT--GKPVAS-ITDVTVTNI 354 Query_10003 296 NITFVGNGDSSSNGARIKIWAGPV-GSAIVNDIHYEDITVMWVT-NPLVVDSCYFSQAYCAT--GKAVAS-ITDVTVTNI 370 Query_10004 299 NVTFVGNGDRSSNGARIKWWAGPV-GSAIVNDVHYEDITVDNVA-NPLVVDSCYFSQAYCATVRGKPVAS-ITNVTVTNV 375 Query_10005 299 NVTFVGNGDRSSNGARIKVWAGPV-GSAIVNDVHYEDITVDNVA-NPLVVDSCYFSQAYCATVRGKPVNAS-ITNVTVTNV 375 Query_10006 295 NITFVGNGDSSSNGARIKIWAGPV-GAAIVNDIHYENITVDNVT-NPLVVDSCYFSQAYCAT--GKPVAS-ITDVTVTNV 369 Query_10007 200 NIWMNK-..--SENGVRIKTFAGQNrGYGTVDNIIYTNFHWVNSD-YPITIDNCYKTSVANCT--TYPSGIKIDNVL..... 268 Query_10008 265 NIWNSD-..-SENGVRIKTFAGQNrGYGIVDNIIYTNFHNWNND-YPITIDNCYKTSVANCT--AYPSGIQINNVFLRNI 337 Query_10009 293 NITFVGNGDSSSNGARIKVWAGPV-GSARVNDVHYEDISWVWVT-NPLVVDSCYFSSAYCAT--GKAVAS-ITNVTVTNV 367

Query_10001 376 KSMGGQY-..-GIRVLAYDHSPVTGLKVTDSEI -...-DGVDIPMELLKhVKDPVFSNLYIInGKRYDSHKA -....... 436 Query_10002 355 RGNSTGA---VVSSIICPEGSTCDIKFKNVDIKP-KNGAAPVYRC--F-SVTSEDLGV-NCTYPTIVNGTFKWPD [360] 781 Query_10003 371 SGNSTGA---VVSSIICPEGSVCDIKFKNVNIKP-KTGVAPVYRC--F-SVTSEELGV-NCTYPTIVNGTFKWPA 437 Query_10004 376 RGNSTGA---VWSSVICPKGSICDIKFKNWNIKP-KTGAAPVHRC--F-SVTSEELGV-KCTYPTIVNGKFKWRA 442 Query_10005 376 RGNSTGA---VVSSVICPKGSICDIKFKNVNIKP-KTGAAPVHRC--F-SVTSEELGV-KCTYPTIVNGKFKWRA 442 Query_10006 370 SGNSTGP-.-VVSSIICPEGSTCDIKFKNVNIKP-KTGAAPVYRC--F-SVTSEDLGV-NCTYPTIVNGTFKWPA 436 Query_10007

Query_10008 338 TGTSSGKYNSTVASLVCSPGACSPVYLQDINLSPPSNYSAASYTCINL-NVTGPSAGL_NCTSGDIIGSLYYPPA- 410 Query_10009 368 TGTSTGK---VWSSIICPEGSTCDIKFKNVNIVP-RTGVAPVYRC--F-SVKSEELGV-NCTYPTVWNGTFKWP- 433

\section{Figure 6}

Multiple alignment of the amino acid sequence of $P$. indica polygalacturonase and Rhizoctonia solani. The dashes exhibit gaps to improve the alignment. Conserved residues, no gaps, gaps are represented in red, blue and gray, respectively. Query_10001: pectinase, Query_10002: Extracellular polygalacturonase (Thanatephorus cucumeris (strain AG1-IA) (Rice sheath blight fungus) (Rhizoctonia solani)), Query_10003: Putative extracellular exo-polygalacturonase (Rhizoctonia solani 123E), Query_10004: 
Putative extracellular exo-polygalacturonase (Rhizoctonia solani 123E), Query_10005: Extracellular exopolygalacturonase, putative (Rhizoctonia solani AG-3 Rhs1AP), Query_10006: Similar to exopolygalacturonase (Thanatephorus cucumeris) (Rhizoctonia solani), Query_10007: Putative exopolygalacturonase X Short=ExoPG (Thanatephorus cucumeris (strain AG1-IB / isolate 7/3/14) (Lettuce bottom rot fungus) (Rhizoctonia solani), Query_10008: Exo-polygalacturonase (Rhizoctonia solani AG-3 Rhs1AP), Query_10009: Exo-polygalacturonase (Rhizoctonia solani 123E).

\section{Supplementary Files}

This is a list of supplementary files associated with this preprint. Click to download.

- graphicalabstract.pdf 